\title{
25 years of JACO
}

\author{
Ilias S. Kotsireas ${ }^{1}$
}

Received: 13 February 2018 / Accepted: 13 February 2018 / Published online: 20 February 2018 (C) Springer Science+Business Media, LLC, part of Springer Nature 2018

The Journal of Algebraic Combinatorics (JACO) has been the top-ranked journal in the research area of algebraic combinatorics for the past 25 years. Founded in 1992 by Chris Godsil, Ian P. Goulden, and David M. R. Jackson, JACO has published close to 1300 rigorously refereed top-quality papers that cover all aspects of algebraic combinatorics and its interaction with other areas of mathematics.

JACO's stature is owed to many factors beginning with the vision of its three founding editors, and continuing with the hard work of its previous Editors-in-Chiefs and the dedicated work of those who have refereed for the journal. Hundreds of researchers around the world have chosen JACO repeatedly as the preferred publication venue for their best work, thus making the decisive contributions to the tremendous success of the journal.

With a current Impact Factor of 0.779 , JACO continues to be globally recognized as the leading journal in algebraic combinatorics. Generations of researchers spanning the full spectrum of academic life, from talented undergraduates students, to motivated graduate students pursuing Master's and $\mathrm{PhD}$ theses, to tenacious junior and senior faculty members at Universities and research institutes, built much of their careers on their JACO publications. This important legacy must be preserved for the benefit of future generations of researchers.

Springer is recognized as a worldwide leader, bringing excellence and innovation to scientific publishing, and as such, has demonstrated an intense interest in better meeting the needs and wishes of academia in today's challenging environments. To this, several initiatives toward free access publication have been implemented, as detailed in Harry Blom's guest editorial in this issue. The new journal Algebraic Combinatorics, whose

\footnotetext{
$凶 \quad$ Ilias S. Kotsireas

ikotsire@wlu.ca

1 Wilfrid Laurier University, Waterloo, ON, Canada
} 
inaugural volume was published in January 2018, is an important and worthwhile initiative in the direction of Open Access publication and clearly demonstrates that the research area of algebraic combinatorics is vibrant enough to sustain two highquality journals. Researchers are thus provided with two different options to consider when they ponder the question of where to submit their work for publication.

It is an immense privilege for me to serve as JACO's next Editor-in-Chief. My approach to this important office is guided by the principle that first and foremost, this is a position of service. At this point I would like to thank the previous Editorsin Chief of JACO, with whom we had a very professional, productive, cordial and effective collaboration, during the transition period. I also want to sincerely thank everyone who has accepted to participate in JACO's Advisory Board and Editorial Board. Our collective efforts will bring forward a vision of how JACO should evolve to better represent (and account for) emerging trends in the interactions of algebraic combinatorics with other areas of mathematics and physics. Moreover, I am very much looking forward to engage in a constructive dialogue with members of the community regarding the future of JACO, and I invite all who are interested to please contact me with their comments, thoughts, and suggestions.

In keeping with the journal's history as well as my own viewpoint, the continued success of JACO will depend on the quality research published in the journal in conjunction with the timeliness of publication. Therefore, my primary focus is to maintain the high standards of the journal and to advance the timeliness of attribution of page numbers. To this, I am in the process of discussing an alternative publishing method with Springer which may be possible to implement in 2019. Many of the readers may be familiar with "Continuous Article Publishing" (CAP). This method is already in place with other Springer journals and means that each article, after peer-review and acceptance, will be published immediately with a DOI and page numbers. ISI Web of Science will index CAP articles immediately and articles will become an immediate part of the journal's analytics. With this special structure, each article begins with page 1. Some may see this as a slight drawback, and some may see CAP as progressive with zero hindrances. I would welcome any reaction from the community to the idea of publishing JACO using a continuous article publishing mode so kindly feel free to send me your thoughts.

Ilias S. Kotsireas

Editor-in-Chief, JACO

Wilfrid Laurier University

Waterloo, ON, Canada 